\title{
Comparison of the performance of a domestic solar water heater in different climates in Algeria
}

\section{Touhami Baki ${ }^{1 *}$}

1 Mechanical faculty, Gaseous Fuels and Environment Laboratory, USTO-MB, BP 1505, ElM'Naouer, Oran 31000, Algeria

* Corresponding author: touhami.baki@univ-usto.dz

Keywords: water heaters; solar; weather; TRNSYS; Algeria

\begin{abstract}
A simulation with TRNSYS of an individual solar water heater for the hot water needs of an average family in Algeria was made; three cities of different climates were chosen to the north on the coast, in the highlands and in a desert region, the solar water heater consists of a flat panel of $4 \mathrm{~m}^{2}$ and a storage tank of 300 liters, a back-up electrical energy is activated when solar radiations are insufficient or during the night, the consumption of domestic hot water leaving the tank at $60^{\circ} \mathrm{C}$ follows a typical profile, the results show significant performance in the south and similar data in the north and in the highlands.
\end{abstract}

\section{Introduction}

Algeria, due to its geographical position, has a very important solar deposit, the duration of insolation varies between 2000 hours in the north and 3,900 hours in the south, and the energy received on a horizontal flat surface varies from 3 in the north to $5.6 \mathrm{kWh} / \mathrm{m}^{2}$ in the south [1]; its climate is subdivided into three zones, Mediterranean type on the fringe of the coast, semi-arid on the high plateaus and desert in the south [2]. Energy consumption for the year 2017 in Algeria reached 44.65 million Tep, of which 15 million or $33 \%$ was absorbed by the residential sector, of this $65 \%$ share represents the consumption of individual dwellings; the breakdown of energy in this sector by type shows a preponderance of natural gas [3]. Solar energy is a renewable and abundant energy, it is particularly suitable for the production of individual domestic hot water. This energy is certainly abundant but it is intermittent and its availability is out of step with the needs; to take advantage of this, it is recommended to install a thermal storage tank.

The widespread use of solar water heaters that can be installed in individual dwellings can save a substantial part of the natural gas used for heating water for sanitary purposes. A growing demand is felt in Algeria and around the world; State aid programs through the APRUE body have been launched for the installation of 400 solar water heaters in 2010, 2000 solar water heaters in 2017 and a new program is in preparation of the year 2020; these programs remain timid and fall short of the country's capacities and potential. Millions of such equipment have been installed around the world, according to a 2012 study [4], and this trend continues to grow over the years. 
The performances of solar water heaters have been intensely studied theoretically and experimentally in recent years, Biaou and Bernier [5] have studied different means of producing domestic hot water from renewable energy, they concluded that the heating with solar thermal collectors with additional electrical energy is the best solution. Buzás et al [6] developed a mathematical model to follow the thermal behavior and the energy balance of solar collectors and hot water storage tanks.

Morrison and Braun [7] developed a model of a thermosiphon solar water heater and compared the results with experimental data. Druck et al [8] experimentally studied several types of solar water heater installation, comparisons were made on the aspect of thermal performance, durability, reliability and environment. Mondol et al [9] carried out the experimental study of a solar water heater with an exchanger placed outside the tank, they concluded that this approach allows rapid heating and savings in installation. Zeghib and Chaker [10] modeled a domestic solar water heating installation, they analyzed more precisely the influence of the thermosyphon flow rate and, therefore, the degree of stratification of the tank on the performance of the water heating system.

Dziugaite-Tumeniene and Streckien [11] compared the simulation of three software programs TRNSYS, Energypro and Polysun for an installation of a solar water heater supplying a family with domestic hot water, in this analysis TRNSYS and Polysun give more convincing results. Mohammed et al [12] simulated a solar water heater installed in Baghdad to supply hot water to a group of 25 people, the annual solar fraction obtained is $69 \%$, at the months of January and February the electrical auxiliary energy is maximum. Baki et al [13-14] studied the performance of a solar water heater installed in Oran, by taking stock of the inputs and outputs of the different energies at the level of the balloon, they concluded that the performances are maximum in the hot months of the year. Baki et al [15] carried out the simulation with TRNSYS of a solar water heater under the typical climate of Oran, the results show an energy saving particularly during the hot months, the electrical back-up energy is at a minimum. Lazreg et al [16] made the simulation of a solar water heater, they followed the stratification of the temperature inside the balloon at several levels for the months of January, June and September and compared the results found.

\section{Case study}

The study concerns the simulation of the performance of the solar water heater, to produce domestic hot water for an individual dwelling, occupied by an average family of 6 people in the climate of cities in Algeria in three different regions, in namely Oran, El Bayadh and Bechar.

\subsection{Solar loop}

The individual solar water heater is composed of a flat solar panel and a tank, these elements are connected with pipes, a pump circulates the heat carrier between the panel and the exchanger located inside the tank; the solar energy absorbed at the level of the panel is converted into heat, and finally transmitted to the balloon through the 
exchanger. The cold sanitary water enters the tank is heated in contact with the exchanger and leaves hot to supply the domestic network, see figure 1 . The flat panel collects solar radiation and heats the circulating liquid, the solar loop ensures the heating of the water inside the tank thanks to a heat exchanger, an auxiliary electric energy with a power of $1 \mathrm{~kW}$ is integrated to fill the deficit and ensure heating at the threshold of 60 ${ }^{\circ} \mathrm{C}$; a control system ensures that the pump is turned on when the outlet temperature of the panel is higher than the temperature of the bottom of the tank, the tank is fully insulated to minimize losses. The solar panel has a surface area of $4 \mathrm{~m}^{2}$ and is inclined at $30^{\circ} \mathrm{C}$ from the horizontal and oriented towards the south. The balloon has a storage capacity of 300 liters.

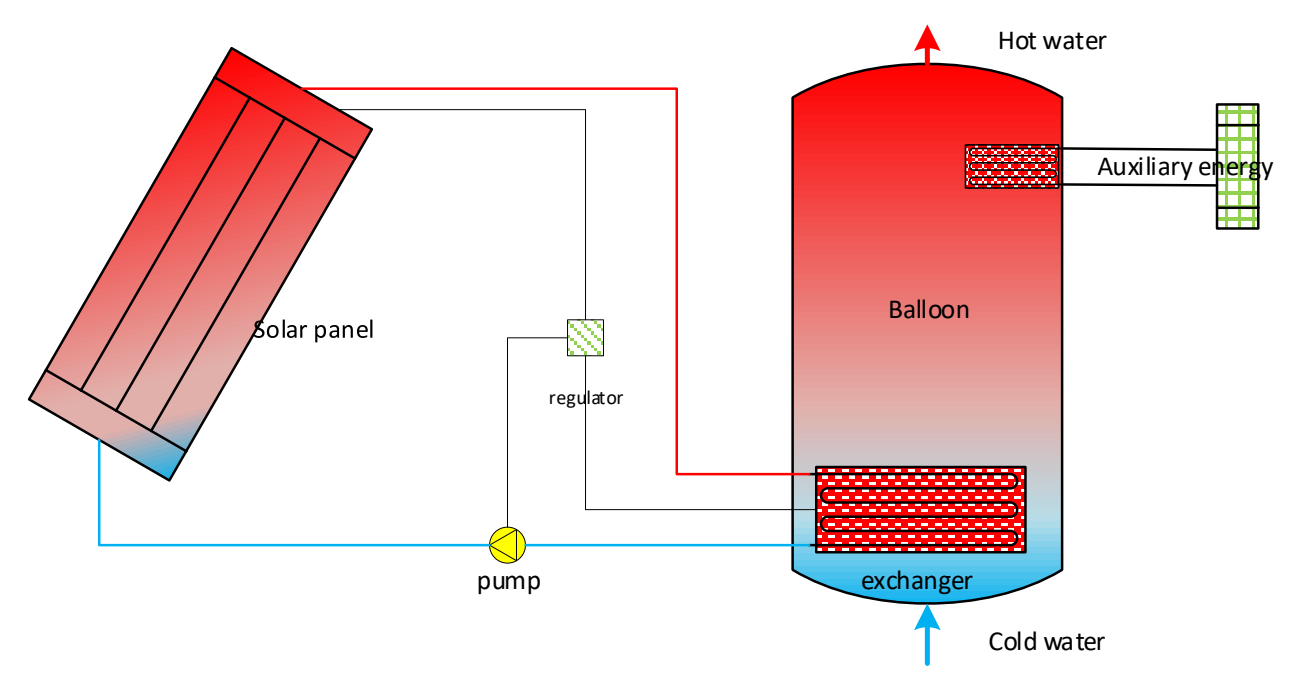

Figure 1. Installation diagram

\subsection{Consumption profile}

The hot water needs are 240 liters per day for an average family of 6 people, the temperature of the hot water at the outlet of the tank is equal to $60{ }^{\circ} \mathrm{C}$, the fraction of the hourly consumption of hot water follows the profile presented in figure 2 ; This profile shows a variability in the draw-off, consumption is zero between 2 a.m. and 5 a.m. and it is maximum around 8 a.m. and 10 p.m. 


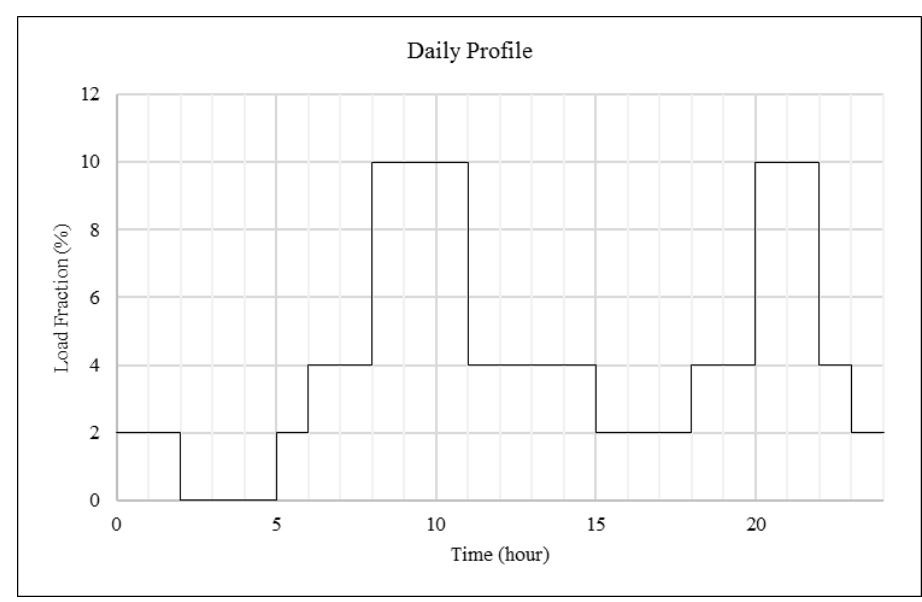

Figure 2. Domestic hot water consumption profile for one day

\subsection{Weather data}

The choice of cities, see figure 3 was made to have specific climates of each region of the country, in Oran coastal city has a warm temperate type climate, classified Csa (Koppen-Geiger), the annual mean temperature is $18.1^{\circ} \mathrm{C}$; El Bayadh enjoys a steppe climate, the annual mean temperature is $14.2^{\circ} \mathrm{C}$, classified BSk; the city of Bechar has a desert climate with an mean annual temperature of $20.2{ }^{\circ} \mathrm{C}$, classified BWh. Figure 4 represents the monthly mean temperature of the three cities, the temperature of the city El Bayadh is the lowest compared to the others, particularly in the cold months; in June, July and August the temperatures of the city of Oran and El Bayadh are similar, the temperature of the city of Bechar is relatively high in the hot months and similar to that of Oran in the month of October to March ; Figure 5 shows the maximum solar radiation obtained during the corresponding month on a plane inclined at $30^{\circ}$ and oriented to the south, the radiations of El Bayadh and that of Bechar are almost similar, that of Oran are lower.

\subsection{TRNSYS schematic}

The simulation was run with TRNSYS 16.0, the chosen parameters are indicated in the following paragraphs, the calculation is done throughout the year with a time step of one hour. The type $60 \mathrm{~d}$ tank has an internal exchanger connected to the type $1 \mathrm{~b}$ solar 


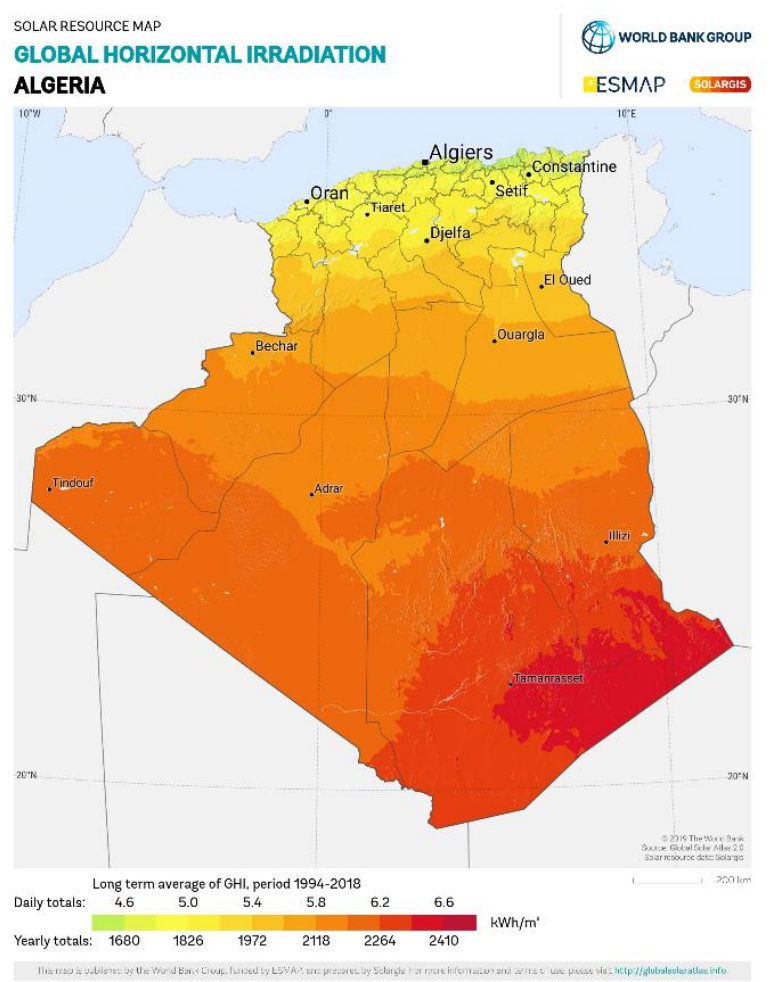

Figure 3. Location of cities with solar potential [17]

panel and the circulation of the heat transfer fluid from the solar loop is provided by the pump $3 b$; the starting and stopping of the pump is ensured by the regulator $2 b$, the water supply profile entering the tank is integrated with the type element $14 b$, the assembly is shown diagrammatically in figure 6 . The meteorological data are taken from the TMY2 file, which aggregates the average of all data, temperatures, and radiation over a 10-year period (200-2009). All the output parameter data are stored in spreadsheet type files; at night or in the absence of radiation, an electrical resistance used as back-up energy is activated so that the temperature at the outlet of the balloon is around $60^{\circ} \mathrm{C}$.

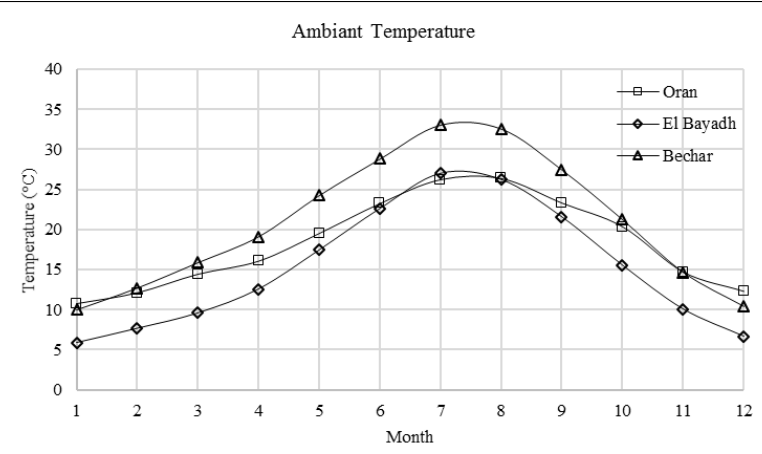

Figure 4. Monthly mean temperature

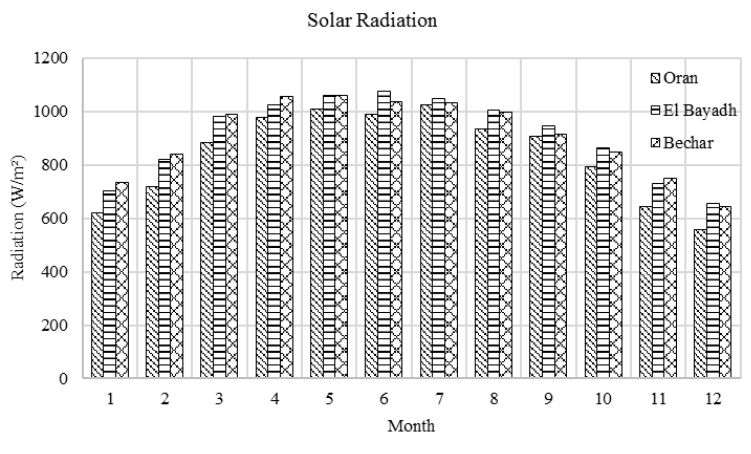

Figure 5. Monthly solar radiation 


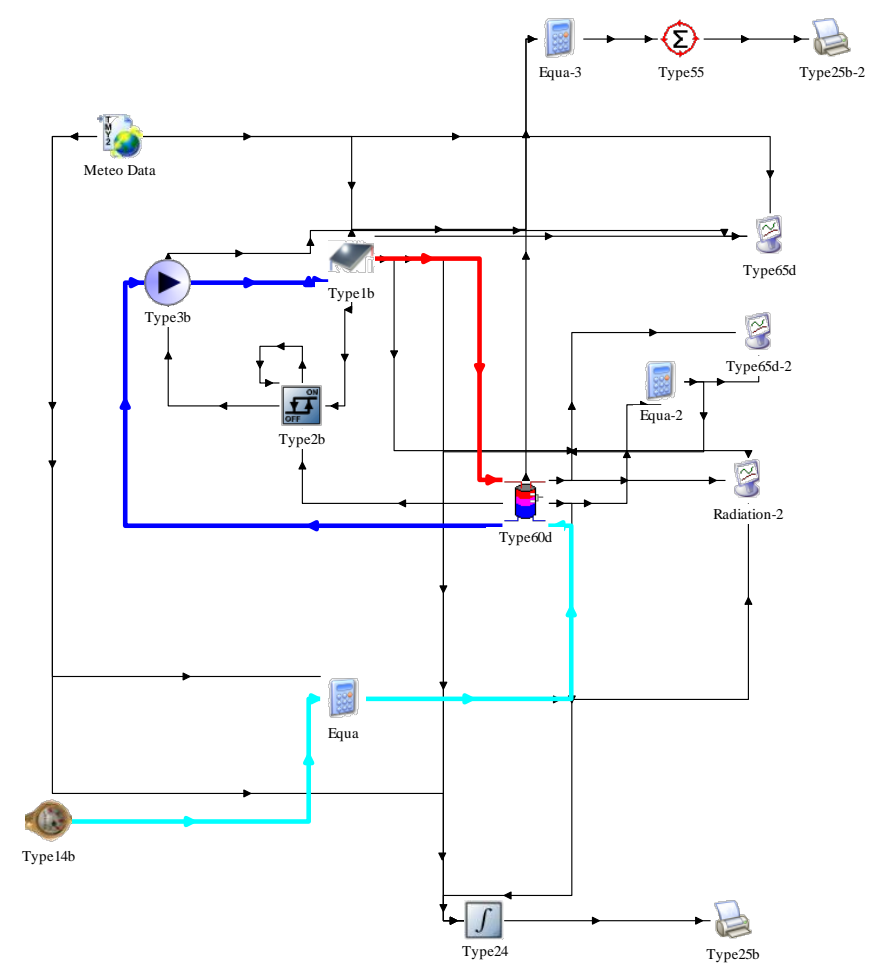

Figure 6. TRNSYS schematic

\section{The results}

\section{1. solar fraction}

By varying the angle of inclination of the solar panel we obtain the variation of the mean solar fraction over a period of one year, with an extremum around $30^{\circ}$, for the three places, as shown in figure 7; for the cities of Oran and El Bayadh the curves are confused, from 10 to $30^{\circ}$ a slight increase beyond a noted decrease; the same for the town of Bechar but with more pronounced variations. similar results were found by Cascetta et al [18], where they investigated the influence of angle on the solar fraction.

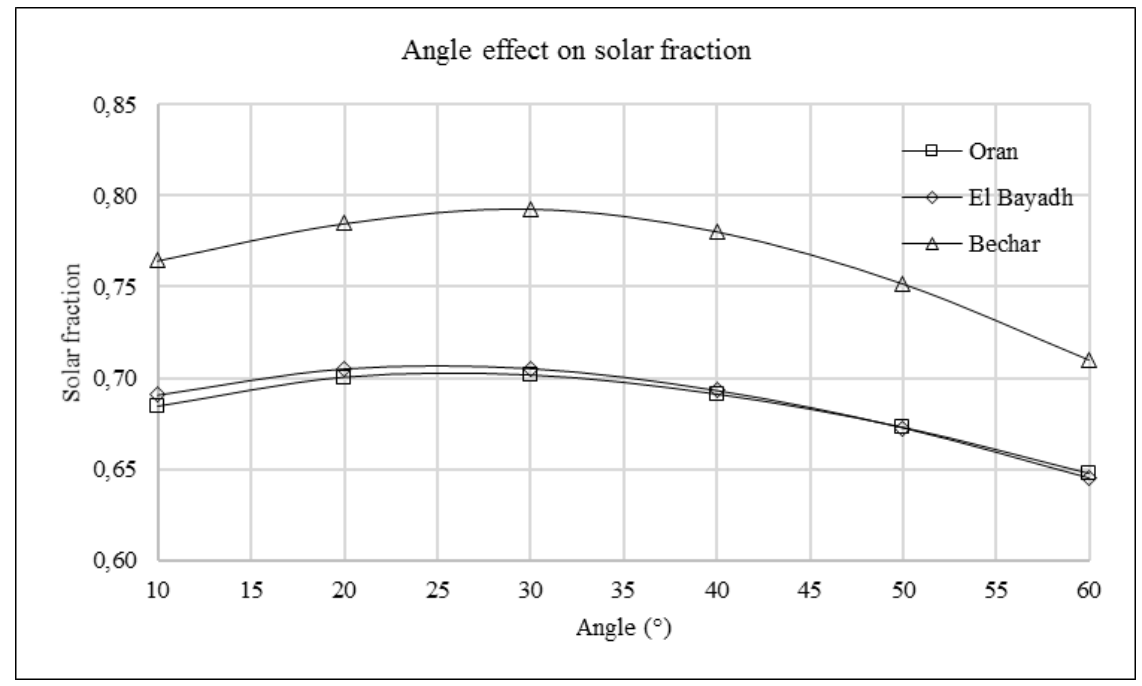

Figure 7. Effect of tilt angle on solar fraction 


\subsection{Useful energy of the panel}

Figure 8 shows the variation in the useful energy recovered by the panel for the three cities, the energy captured in Bechar is the most important during the year, it is exceeded by that of Oran in August, the panel in Oran captures less energy than in El Bayadh except for four months, taking stock over one year, we obtain a total energy of 2.38 in Oran, 2.46 in El Bayadh and $2.82 \mathrm{GWh}$ in Bechar.

\subsection{Energy consumed}

Figure 9 shows the monthly consumption of domestic hot water energy in the three cities, during the hot months the consumption decreases and increases relative to the cold months with variability for each city depending on its climate; overall it varies in the same way for the three regions of the country. The same curves of energy consumption have been presented by Ma et al [19], for several towns in the UK.

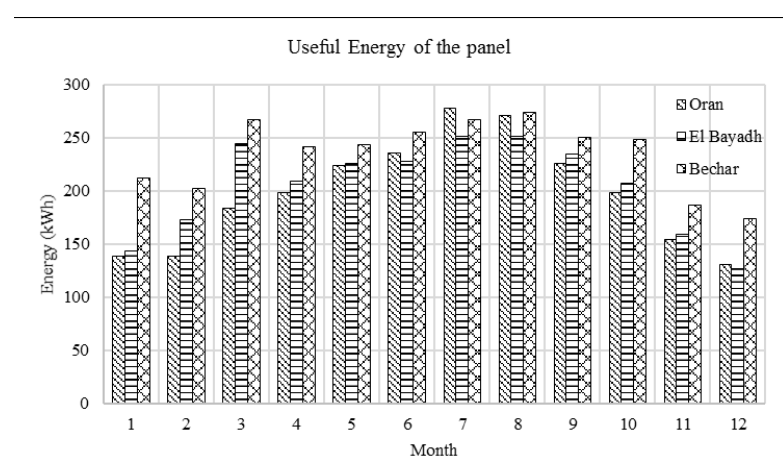

Figure 8. Useful energy of the panel

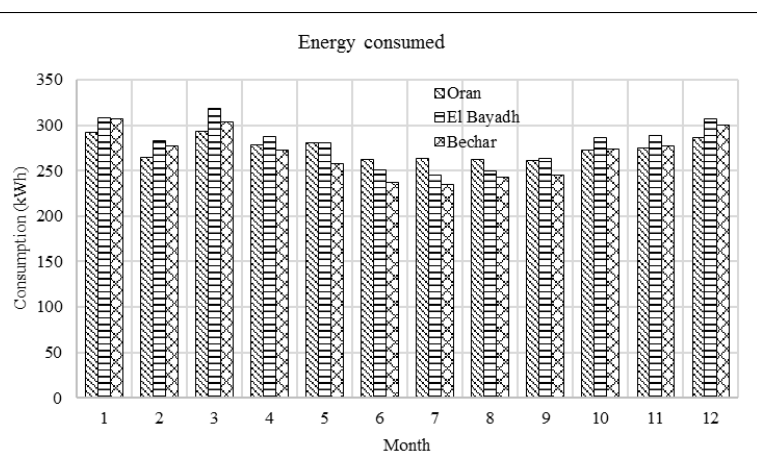

Figure 9. Energy consumed

\subsection{Auxiliary energy}

The monthly auxiliary energy demand is presented in figure 10, it clearly shows that the needs are minimal in hot weather and that they increase during the cold months, the annual report shows that the cities of Oran and El Bayadh have needs in similar energy, namely $1.53 \mathrm{GWh}$ at Oran and $1.56 \mathrm{GWh}$ at el Bayadh, on the other hand at Bechar the needs are reduced to $0.99 \mathrm{GWh}$. The auxiliary energy curve of a solar water heater installed in Baghdad shows a decrease in consumption in hot months according to Mohammed et al [12], similar to that presented in figure 10. 


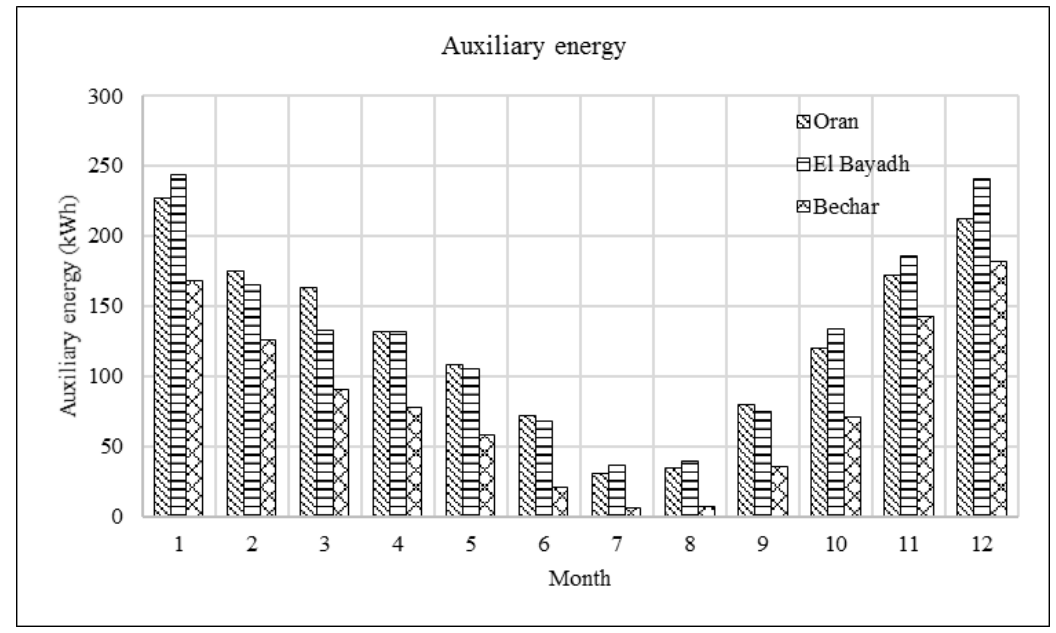

Figure 10. Auxiliary energy

\section{Conclusions}

A comparative study was carried out between three regions of Algeria, each with its own particular climate. Ambient temperatures and radiation received by the panels vary from region to region, temperatures in Bechar remain highest, Oran are moderate, and El Bayadh are cold in winter and hot in summer.

The useful energy recovered by the panel is relatively high in Bechar and similar in Oran and El Bayadh. The consumption needs remain the same since we have maintained the same parameters for the three cases. The auxiliary energy needed to make up the deficits is lowest in Bechar and the same in the other towns.

Acknowledgments: The author addresses the sincerest thanks to Professor Driss Nehari for his help.

\section{References}

[1] Internet site of the Energy Minister, https://www.energy.gov.dz/ rubrique énergies nouvelles renouvelables et maitrise de l'énergie

[2] Internet site of Algeria Weather https://www.meteo.dz/climatenalgerie.php

[3] http://www.aprue.org.dz/documents/publication de consommation énergétique finale.

[4] Weiss, W., \& Mauthner, F. (2010). Solar heat worldwide. Markets and contribution to the energy supply.

[5] Biaou, A. L., \& Bernier, M. A. (2008). Achieving total domestic hot water production with renewable energy. Building and Environment, 43(4), 651-660.

[6] Buzás, J., Farkas, I., Biró, A., \& Németh, R. (1998). Modelling and simulation aspects of a solar hot water system. Mathematics and Computers in Simulation, 48(1), 33-46.

[7] Morrison, G. L., \& Braun, J. E. (1985). System modeling and operation characteristics of thermosyphon solar water heaters. Solar Energy, 34(4-5), 389-405.

[8] Druck, H., Heidemann, W., \& Muller-Steinhagen, H. (2004, June). Comparison test of thermal solar systems for domestic hot water preparation and space heating. In Proceedings of EuroSun (pp. 20-23).

[9] Mondol, J. D., Smyth, M., Zacharopoulos, A., \& Hyde, T. (2009). Experimental performance evaluation of a novel heat exchanger for a solar hot water storage system. Applied Energy, 86(9), 1492-1505. 
[10] Zeghib, I., \& Chaker, A. (2011). Simulation of a solar domestic water heating system. Energy Procedia, 6, 292-301.

[11] Dziugaite-Tumeniene, R., \& Streckien, G. (2014). Solar Hot Water Heating System Analysis Using Different Software in Single Family House. In Environmental Engineering. Proceedings of the International Conference on Environmental Engineering. ICEE (Vol. 9, p. 1). Vilnius Gediminas Technical University, Department of Construction Economics \& Property.

[12] Mohammed, M. N., Alghoul, M. A., Abulqasem, K., Mustafa, A., Glaisa, K., Ooshaksaraei, P., Sopian, K. (2011). TRNSYS simulation of solar water heating system in Iraq. Recent Researches in Geography, Geology, Energy, Environment and Biomedicine, 153-156.

[13] Baki, T., Tebbal, M., Berrebah, H., \& Bougara, F. Etude des performances d'un chauffe-eau solaire individuel installé à Oran. 1ère Conférence Sur Les Energies Renouvelables \& Les Matériaux Avancés ERMA'19 - Relizane, Algérie le 16 et 17 Décembre 2019.

[14] Baki, T., Tebbal, M., \& Berrebah, H. Following the Balloon Temperature of a Solar Water Heater Installed in Oran, Algeria; 5 International Anatolian Energy Symposium, 24-25 March 2021, Karadeniz Technical University, Trabzon/Turkey.

[15] Baki, T., Nehari, D., Remlaoui, A., El Merieh, A., Madani, M., (2019). Simulation d'un chauffeeau solaire individuel sous un climat typique d'Oran, International Conference on Renewable Energy and Energy Conversion, ICREEC'2019, Oran 11-13 November.

[16] Lazreg, M., Baki, T., \& Nehari, D. (2020). Effect of Parameters on the Stratification of a Solar Water Heater. In ICREEC 2019 (pp. 117-125). Springer, Singapore.

[17] Internet site: https://solargis.com/maps-and-gis-data/download/algeria

[18] Cascetta, F., Cirillo, L., Della Corte, A., \& Nardini, S. (2017). Comparison between different solar cooling thermally driven system solutions for an office building in Mediterranean Area. Int J Heat Technol, 35, 130-8.

[19] Ma, Z., Bao, H., \& Roskilly, A. P. (2018). Feasibility study of seasonal solar thermal energy storage in domestic dwellings in the UK. Solar Energy, 162, 489-499.

(c) 2021 by the authors. Licensee UAIC, Iasi, Romania. This article is an open access article distributed under the terms and conditions of the Creative Commons Attribution (CC BY-NC-ND) license (https://creativecommons.org/licenses/by-ncnd/4.0). 